\title{
Illusioned and Alienated: Can Gig Workers Organise Collectively?
}

\section{Dragana Mrvos}

University of South Florida, Saint Petersburg, USA, dmrvos@usf.edu, https: / /www.usf.edu/arts-sciences/departments/school-of-interdisciplinaryglobal-studies/people/dmrvos.aspx

\begin{abstract}
By studying the fraudulent benefits of flexibility in the ride-hailing gig economy, this article explains alienation as a condition in which workers are excluded from the product, estranged, and disadvantaged. Material estrangement, an objective aspect of alienation exemplified by arbitrary distribution of income, capitalists' exclusive access to data, and robotic communication between Uber and their drivers, has many physiological (subjective) manifestations. Dissatisfaction, powerlessness, and isolation as subjective expressions of alienation prominently shape the prospects of collective labour mobilisation by both sparking and hindering organisational potential. Additionally, the example of workers' re-appropriation of Uber's app against Uber explains how modern technologies serve not only as a medium to expand capitalist interests, but enhance possibilities for labour cooperation and liberation. The proposed argumentation uses the Autonomist Marxist concept of "social factory" as a metaframework, drawing on original ethnographic and interview data on ride-hailing Uber drivers in the gig economy.
\end{abstract}

Keywords: Uber, dissatisfaction, powerlessness, isolation, labour mobilisation, reappropriation

\section{Introduction}

The term 'gig economy' describes workers who "have gigs instead of jobs" (Zwick 2018, 680). Unlike traditional employment, temporal and contractual gigs endorse work flexibility, variety, and passion ("work whenever, wherever") (Torpey and Hogan 2016). The acceleration and turnover rates of gigs are much higher now compared with the time when so-called "temp agencies" (e.g. Manpower Inc.) started providing temporal and contractual workforce in the late 1950s (Hyman 2018, 1-2). Out of the total United States workforce, "more than 1 in 4" workers engage in the gig economy (Gig Economy Data Hub 2020).

The intriguing question of why so many people take on freelancing, including platform-based and other independent work, has a proposed scholarly justification that most people engage in these types of work by choice and because they enjoy flexibility (Oyer 2020, 2).

Still, the 'price' of flexibility cannot be fully accounted for without capturing the working conditions of gig labour more substantially. I aspire to understand the broader logic and operation of gig businesses by closely engaging with the direct experience of workers, which leads me to openly question the assertion that many gig workers choose (rather than being obliged to take on) 'gigs'. Furthermore, this article asks how capitalist relations lead to alienation, including its objective and subjective elements. In particular, how does the material estrangement of workers (exploitation) manifest, and what subjective manifestations does it have? Ultimately, how do the 
subjective aspects of alienation shape the prospects and manners in which labour mobilisation takes place?

Uncontrolled service charges and commission fees, coupled with capitalists' exclusive access to data and the robotic communication between Uber and their drivers, represent aspects of the estrangement of those drivers, leading to widespread dissatisfaction, powerlessness, and isolation. Dissatisfaction and powerlessness, being the two key aspects of subjective alienation, lead workers to organise collectively to advance their power and influence in society. Simultaneously, isolation, as the third aspect of subjective alienation, prevents the outgrowth of workers' struggle into a more sustainable movement. The example of workers' appropriation of Uber's app against Uber also explains how modern technologies can serve not only as a medium to expand capitalist interests, but also to enhance possibilities for labour cooperation and liberation.

I begin the discussion of alienation under the gig economy by explaining Marx's view of alienation under capitalism. I then use the Autonomist Marxist concept of "social factory"1 and far-reaching control facilitated through modern technologies to theoretically frame the argumentation in this article.

This article draws on original empirical findings in analysing alienation and collective labour mobilisation amongst Uber drivers and concludes by summarising the findings in light of theoretical notions of the social factory and the power of technology. It also calls attention to new ways of collective struggle, targeting capitalism and the social antagonisms rooted therein.

\section{Alienation}

Broadly defined, alienation signifies a condition in which people are estranged and disadvantaged. According to Marx, alienation represents the commodification of labour and estrangement from the product, self-estrangement, and estrangement from species-being (Tucker 1978, 73-77). Alienation also "displays the devastating effects of capitalist production on human beings, on their physical and mental states and the social processes of which they are part" (Ollman 1971, 131). Given that "all is under the sway of inhumane power", referring to the extension of capitalist logic onto the totality of life as a "social factory", "man's existence has become the purpose of work" instead of "life being an opportunity to work" (1971, 132; 153).

Similarly, Harvey $(2018,427)$ implies that capital ("objective garbs") produces alienation, which has many physiological implications ("subjective garbs"). In the economy, workers 'freely' sell their labour-power, but the significant portion of the value they create is appropriated by capital (exploitation) $(2018,426)$. Moreover, the value of labour-power returns to the workers only as a commodity, while their potential for initiative, mutual support, and other social skills diminishes (2018, 426-427).

When humans do not control "the conditions, processes, and products at work", alienation extends into general social conditions (Fuchs 2020, 198). The more workers become socially and materially deprived, the more they feel passive, resentful, depressed, and prone to alcoholism, drug abuse, or suicidal behaviour (Harvey 2018, $424 ; 429)$. Dyer-Witheford $(2015,4)$ exposes numerous stories of labour despair, including the example of "antisuicide nets hanging outside the Foxconn factories where iPhones rolled off the production lines" to prevent self-harming behaviour among the workers.

\footnotetext{
${ }^{1}$ See Witheford (1994).
} 
Without the possibility of using legitimate ways to "take control of the structures that affect their lives" (Fuchs 2020, 198-199), workers feel that they do not receive what they deserve. In the case of Uber drivers, the uncontrolled service charges and commission fees observed in the distribution of income, capitalists' exclusive access to data, exemplified in the phenomenon of surges, and the robotic communication between company and drivers represent aspects of the estrangement leading to widespread dissatisfaction and powerlessness.

Capitalists' unilateral access and control of information ("unilateral surveillance") aimed at predicting and modifying workers' behaviour (Zuboff 2019, 19; 67) contributes to another manifestation of subjective alienation; that is, isolation. Workers do not recognise the "bigger picture" and have difficulty understanding "what they are creating, for who[m] and to what purposes" (Anwar 2018), which I explain through the tenuity of connections and the mutual suspicion preeminent amongst Uber drivers.

It is also worth noting that "subjective alienation may remain a pure individual expression" or "take on collective political forms that advance class struggles, political protests, and struggles for recognition" (Fuchs 2020, 202). The dominated and oppressed do not necessarily hate their oppressors: "objective alienation does not necessarily result in feelings of alienation" (Fuchs 2020, 202). Similarly, Marx states that we come to feel "at home" in an estranged world (Tucker 1978, 74).

However, there is always something fraudulent about the exchange between the capitalists and the workers (Harvey 2018, 426). In the context of "social factory" (Witheford 1994, 94) explained in the next section, modern technologies mystify objective alienation by managing the exploitation of workers in more stylish ways, but workers are still exploited (i.e. "the surplus-value is appropriated from the actual producer" (Wolfson and Funke 2018, 581)). Therefore, "objective alienation always contains potentials for resistance and feelings of alienation" (Fuchs 2020, 202), the establishment of which is the primary goal of my approach towards alienation. I aim to show how dissatisfaction and powerlessness lead workers to organise collectively to advance their power and influence in society, while isolation prevents the outgrowth of worker struggle into a more sustainable movement.

\section{The "Social Factory" and Technology}

This section develops from the concept of "social factory", suggesting that labour environment and exploitation are no longer limited to the factory and plant (Lamas et al. $2017,58)$. Tronti (2019) argues that the more capital reaches "the unity of the labour process with the process of valorisation", the former referring to the consumption of the means of production by the worker as material for his or her productive activity, while the latter refers to the capital that develops into command over the worker (i.e. compelling the working class to surplus-labour), the more "the capitalist form of production becomes the master of all the other spheres of society, invading the entire web of social relations" (49). A distinction between "the paid and unpaid parts of labour become inseparably confused", and value, "in which is represented the actually paid part of the working day, should appear, then, as the value or price of the labour day as a whole" (Tronti 2019, 50).

In the gig economy, ride-hailing platforms such as Uber do not pay their drivers for "the labour-time required to produce a given number of products" (i.e. the time they spend online waiting for rides) (Diab 2019, 139). Drivers' earnings reflect "piecewage work", the time during which they actually provide the ride (Diab 2019, 139). As a result, a driver can spend an unlimited number of hours logged in and working on Uber's platform without being paid. 
Tronti $(2019,50)$ then rightly indicates that "the more that capitalist production [...] develops, the more the paid and unpaid parts of labour become inseparably confused". Simultaneously, "the greater the penetration and extension of the production of relative surplus-value [...] the relation between capitalist production and society, between factory and society, between society and state, becomes increasingly organic" $(2019,59)$.

In the context of the "social factory" as a meta-framework, modern technologies open endless new possibilities for capitalists to mystify bourgeois social relations, to comparatively increase profit, and to expand spatially by paying workers less (Tucker 1978, 215-216). Marx, in Tucker's The Marx-Engels Reader (1978), expresses his concerns toward technological innovation in the hands of capitalists as follows:

If machinery be the most powerful means for increasing the productiveness of labour-i.e., for shortening the working-time required in the production of a commodity, it becomes in the hands of capital the most powerful means, in those industries first invaded by it, for lengthening the working-day beyond all bounds set by human nature. It creates, on the one hand, new conditions by which capital is enabled to give free scope to this its constant tendency, and on the other hand, new motives with which to whet capital's appetite for the labour of others (404).

The quoted paragraph conveys that technology alone does not transform society, but serves as a medium; it facilitates the expansion of capitalists' interests by opening infinite new possibilities for capitalists to exploit workers and increase profits ${ }^{2}$ (Kayıhan 2018, 633; Tucker 1978, 215-216).

Besides the dominative role, technology in the hands of workers can help them appropriate their "own general productive power" by enhancing their possibilities for cooperation (Fuchs 2018, 524; Hope 2018, 569). In support of this, I demonstrate how Uber drivers used modern technologies (e.g., Uber app) against the company. However, I also draw attention to the increasing challenges workers face to sustain organised resistance.

Capitalists often enjoy the right to use technology and data arbitrarily and reshape the position of drivers within the production relation. As an illustration, computers and advanced software are "trained to track and respond to market conditions and dynamically adjust [...] prices every few minutes" (Schiller 2017). However, it is rare that anyone beyond company executives knows the price adjustment formulas or how much the companies benefit from "dynamic pricing" (2017). As the level of control increases, "surveillance capitalists" hold unprecedentedly more knowledge (and thus power) compared with workers (and consumers) (Zuboff 2019, 11).

A comparison of workers' wages for traditional versus ride-hailing drivers illustrates how capitalists can manipulate the concepts of "dual demand" and "dynamic pricing" in the gig economy (Shapiro 2019, 9). The former implies that workers "are consuming the platform [...], just as customers have a need for the services those workers provide" $(2019,9)$. The latter concept suggests that the market determines drivers' earnings, providing them with an opportunity to earn more than "fixed" wage earners, and those who work for the minimum wage $(2019,9)$.

\footnotetext{
${ }^{2}$ Although higher and more complex employments substitute simpler and more subordinated ones, "a mass of workers who have been thrown out of one branch of industry owning to machinery" can hardly "find refuge in another unless the latter is lower, worse paid" (Tucker 1978, 215-216).
} 
As impactful as it sounds, the logic of wage and earning distribution is not reconceptualised in workers' favour. For instance, Uber discloses pick-up and drop-off location, mileage, and earnings distributions for each completed trip. Still, drivers do not have access to critically important data that the company collects during 'disengaged' time. Workers often drive empty miles towards surge areas, which Uber sets based on market conditions, offering higher compensation for rides when demand significantly surpasses supply. By using the surge model, Uber can effectively direct drivers' decisions in the performance of their work without guaranteeing their being paid.

Additionally, gamification ${ }^{3}$ allows the platform and its customers to control and discipline drivers "if and when they feel like it in essentially unpredictable or unknowable ways" (Acevedo 2018, 817). While control of drivers' performance actively increases, the company simultaneously takes away a significant percentage of drivers' earnings through commission fees, services charges, selling personal data, and so on (Muzellec et al., quoted in Munn 2019, 9). My study builds on these insights and analyses the original empirical data, combining direct-participant ethnography, interviews, and document analysis, as explained in the next section.

\section{Methodology}

Although the gig economy encompasses "crowdwork" and "work on-demand via apps" (De Stefano 2016), the former referring to "the completion of work tasks via online platforms" and the latter assuming "in-person execution of traditional working activities [...] channelled through apps managed by firms" (De Stefano 2016, 1). This article concentrates on the latter.

Based on the size of the workforce, Uber represents the leading platform for "work on-demand via apps" (Smith and Leberstein, quoted in De Stefano 2016, 1). To date, Uber operates in 63 countries with 15 million trips a day (PBS NewsHour 2019). More importantly, Uber's expansion and capacity to transform working conditions and earnings speak to capitalism's future and its impacts on labour more generally, as well as to alienation and worker organisation more specifically.

For instance, since Uber initially entered the Tampa Bay market in Florida in 2014 and succeed in legalising its service in 2016 without any particular permits or licenses, it effectively transformed "the transportation scene" (McMorrow-Hernandez 2016; Johnston 2019). As a result, Uber and other platform apps have effectively monopolised transportation services in Tampa, making a comparison of working conditions, alienation, and organisation between taxi and Uber drivers in Tampa unsuited.

By offering cheaper rides than a regular taxi cab, Uber widely popularised a method of passing the cost of lowered prices onto drivers. The platform companies initially subsidise the cost of rides up to $50 \%$ or more when entering new markets to attract more customers, causing heavy financial losses (Kaminska, quoted in Munn 2019, 7). Simultaneously, platforms "adopt the profit-making practices [...] however debilitating for workers" in the name of competition (Munn 2019, 10). Therefore, I pursued a better understanding of the relationship between the economic and the psychological aspects of working as an Uber driver, which required a commitment to direct experiences and "continuous exposure and engagement with a research setting" (Schensul et al. 2012, 2).

3 "Gamification" implies the usage of "game elements" such as point-scoring, levels, and ratings in non-game environments (Mason 2018). No one tells Uber drivers when or how much to work, but stars, bonuses, and badges effectively impact workers' behaviour. 
I completed 103 rides as an Uber driver in Tampa Bay during the month of June 2018 and interviewed 20 Uber drivers, also in Tampa Bay, from October 2018 until February 2019, meeting the informants in person. The targeted group comprised people between the ages of 18 and 75 who work (or had previously worked) as Uber drivers in the Tampa Bay area. I had the sole responsibility of informant recruitment. While driving for Uber, I occasionally met other drivers at the Tampa International Airport Staging Area, where Uber drivers gather and wait for riders' requests. I introduced myself and my research whenever the opportunity arose. Additionally, I asked those who appeared interested in my research to meet me individually and encouraged them to refer me to their co-workers. If they knew other drivers willing to participate in my study, I welcomed such contacts. In that sense, snowball sampling was used in my methodology. Since Uber does not have a public record of its drivers, I could not engage in random sampling. However, I tried to balance my sample across gender, age, ethnic, racial, and educational background.

Of 20 participants, two were between the age of 18 and $25(10 \%)$. Eight informants were between 26 and $35(40 \%)$, three between 36 and $45(15 \%)$, six between 46 and $55(30 \%)$, and one older than $56(5 \%)$. Six informants were female drivers $(30 \%)$ and fourteen were males $(70 \%)$. The majority held a high school certificate $(65 \%)$. Four participants $(20 \%)$ had a bachelor's degree; two $(10 \%)$ held a master's degree. Only one participant had not finished school. Across the racial background, participants in my sample were primarily white $(65 \%)$, followed by Black or African American (15\%), and mixed-race (15\%). One participant was Asian (5\%). I did not interview anyone who identifies as American Indian or Alaska Native, or Native Hawaiian or Other Pacific Islander. Between the two ethnic categories, fourteen participants were not Hispanic or Latino $(70 \%)$, while the remaining six were Hispanic or Latino (30\%).

I complemented personal and interviewing materials with information from a great variety of primary sources, such as blogs, newspapers, talk shows, and the official company's data release. The mixed-method approach allowed me to understand how platforms impact society and its workers. For instance, I realised that financial insecurity (e.g. low pay, driving empty miles, unpaid time in the so-called 'queues' by the airports, and difficulty in 'catching' surges) re-emerged as the least appreciated aspects of driving for Uber. I could then subordinate and draw upon my personal experiences and drivers' insights about economic estrangement and its impacts on alienation.

Nevertheless, 'measuring' psychological implications caused by economic estrangement was challenging. I did not use a numerical scale, nor did I quantitatively code the answers. As a result, I was unable to quantify the scores or create any general scores of alienation amongst Uber drivers (which could later be compared with 'scores' of alienation in other (non-)gig professions).

At the expense of generalisation, by asking informants about the most and least satisfying aspects of partnering with Uber and requesting that they describe their regular working day, I learned how they felt about Uber's rules and norms. By posing questions regarding their "personal impact on Uber's decisions", I learned about communication between Uber and its drivers as well as the latter's fears and insecurities. By inviting each informant to discuss the questions "do you get to know other Uber drivers, how often, and where", and to explain participation in collective organisation or initiative by Uber drivers (if any), I gained a great deal of information on isolation. 
Additionally, photographic and video material captured while in the field were of tremendous help in reconstructing events and narratives authentically. As a result, "thick descriptions" and "meaningful structures" in terms of how workers' behaviour was produced, perceived, and interpreted was the most valuable aspect of a qualitative approach (Geertz 1973, 5-7). As I gained knowledge directly from informants, I used and interpreted the stories to develop an explanation of the fraudulent benefits, alienation, and attempts of collective organising discussed in the following sections.

\section{Dissatisfaction and Powerlessness}

My goal in this section is to illustrate the widespread dissatisfaction and powerlessness of ride-hailing drivers as aspects of subjective alienation caused by material impoverishment and restricted channels of communication between drivers and the company.

Practically, Uber has the unrestrained ability to take any percentage of income from each ride while drivers have no choice but to consent. Per the Rasier Technology Services Agreement $(2015,7)$, Uber Services is only appointed as a "limited payment collection agent solely for the purpose of accepting the Fare, applicable Tolls and, depending on the region and/or if requested by [driver], applicable taxes and fees from the User" on behalf of drivers, but the Company "reserves the right to change the Fare Calculation at any time in the Company's discretion". The company is only obliged to provide a driver with notice if the fare calculation changes. A driver, by accepting a ride, immediately indicates consent to any changes that occur (Technology Services Agreement 2015, 7).

Fares vary by region, depending "on local supply and demand", and may be adjusted at the company's discretion "based on local market forces" (Rasier Addendum 2017). For instance, during the time I drove UberX in June 2018, the service fee was calculated on a Per-Ride basis (Rasier Addendum 2017). It equated to "the Rider Payment minus: (a) the Fare; (b) Tolls; (c) any other fees retained by us (e.g., booking fee); and (d) applicable taxes and surcharges" (Rasier Addendum 2017).

In Tampa, UberX earnings were measured by totalling the base fare $(\$ 0.75)$, distance ( $\$ 0.6528 \times$ miles), and time ( $\$ 0.0884 \times$ minutes). As an illustration, one of my regular Monday morning rides in Saint Petersburg could generate an income of $\$ 7.20$ (base rate of $\$ 0.75$, plus 7.57 miles $\times 0.6528$, plus 17.04 min (expressed decimally) $\times$ $\$ 0.0884)$.

The most I earned for a single ride was $\$ 24.92$. That ride occurred on Friday June 15, 2018, at 4:18 PM. I drove 29.79 miles and spent 53.29 minutes from the pick-up to the drop-off location. For this particular ride, Uber received a total of $\$ 17.52$ (service fee of $\$ 15.07$ plus a booking fee of $\$ 2.45$ ). Based on the total of 103 trips I completed on Uber, I received $56.18 \%$ of the total amount charged for rides. Uber took $43.82 \%$. Although the company appropriates considerably high amounts from each fare, drivers have no input into fare calculations.

Drivers also felt dissatisfied and powerless because they could not control Uber's 'surge model'. The price of their work adjusts based on the supply of drivers interested in "consuming" the platform at any time and demand for rides (so-called "dynamic pricing") (Shapiro 2019, 9). To balance the two sides, Uber uses different manipulative methods such as the surge model.

A surge occurs when demand for rides exceeds supply, creating the possibility for drivers to earn more money than regular rates (x1.5, $\mathrm{x} 2$, or more). Surges were most likely to occur during busy concert nights, in the downtown area after the bars closed, or in beach areas at weekends. Therefore, being active on the Uber platform around 
2 or 3 a.m. would create more opportunities for more earnings. However, simultaneously, platform companies could easily manipulate the surge model, such that it was full of uncertainty for drivers.

For example, one driver who followed surges carefully did not find the practice worthwhile after considering all the potential risks of driving late nights and the costs of driving empty miles. Based on her experiences, the surge model entailed high levels of ambiguity.

According to one driver, Uber once advertised New Year's Eve as an excellent possibility for drivers to catch surge rates and acquire extra income. The same driver decided to drive during New Year's Eve, hoping she would earn a lot of money. The decision to forgo going out with her friends to celebrate that night and to work instead seemed promising, but eventually she "made nothing". She explained that "the night was just like any other, even worse". Her message for Uber was: "Don't tell me the surge will be good if the surge might be good, but might not be good. Give me something to make me drive that night. Do not make me bail". This driver felt as though she was gambling because Uber does not release information about the actual supply and demand at any given point in time. Therefore, freedom deprived of information rarely served to improve drivers' positions, but certainly helped the company to balance supply and demand, especially keeping in mind "constraints of worker flexibility" (Shapiro 2019, 12).

Other informants also questioned the value of driving to the surge, given the additional amount of time needed to get out of traffic in surge areas. As an illustration, driving 5 miles would generate $\$ 3.264$ in earnings compared to $\$ 0.442$ or 44.2 cents for 5 minutes of waiting in traffic (based on time/mile value during June 2018). Because driving more miles paid more than the time a driver would spend in traffic not moving, some drivers concluded that if they were already in the surge area and a surge happened, that would be great. Otherwise, they would not drive to the surge zone, mainly because Uber's boundaries for surges were very "blotchy" (i.e. "down that road, 10 feet away it would count as a surge, but not here where I was", according to one driver).

Along with surges, Uber played a decisive role in drivers' decisions to accept a long ride without actually benefiting, based on the option of "search along the set route". That is, the Uber app displays a "warning" before a driver decides to accept rides with an approximate time of more than 45 minutes. Some informants agreed to drive long trips presuming they could, at all times, take advantage of the driver's ability to a) "set a destination and, if needed, a time [the driver] want[s] to arrive" and b) pick up additional riders: "the app will find riders along the way" (Uber 2018). Nonetheless, numerous informants observed that the algorithm would not find any rides along the route. As drivers could only search trips once every 24 hours, a ride home without making any money exemplified an additional instance of an illusory gain in the gig economy.

Although many drivers believed it would be beneficial to talk to Uber representatives, particularly regarding problematic situations (e.g. problems with payment, traffic incidents, passenger behaviour), drivers could contact Uber only through the app and, rarely, over the phone. In this case, estrangement manifests through restricted channels of communication, preventing drivers from communicating their concerns and the most pressing problems to superiors in the company. Drivers therefore felt utterly powerless, since they could neither influence any decisions nor effectively channel their concerns. 
I spoke with one driver who explained the possibility of contacting Uber through the app any time a driver is unhappy with something. For example, if a passenger does something antisocial, a driver can report it. However, drivers are not able to communicate with Uber representatives often. Even when they do, as this driver put it, "you feel like you're talking to a wall [...] not a very good customer service". Other drivers also complained about Uber's customer service, describing it as "very robotic", or "one-way communication".

Similarly, another informant raised concerns about the quality of assistance that drivers received from Uber customer service representatives, given that Uber hired and paid their customer service agents in the same manner as their drivers. Agents were paid based on the number, not the quality, of requests they addressed. The informant added that customer service grew increasingly automated, making situations in which communication happened over the phone a rare exception (e.g. in the case of serious safety issues) and contact through email a norm. When a driver faced and reported severe safety concerns (a passenger who grabbed the driver's wheel during the ride), he spoke to an Uber representative. Still, he did not know whether Uber banned the reckless passenger from the platform, or what measures, if any, were taken. The status of working as if 'playing a game of dice' has another well-documented physiological manifestation, isolation, which is discussed in the next section.

\section{Isolation}

Earlier I pointed to the power of technology and platform's algorithms in the hands of capitalists within the context of increasing capitalists' profits and the extension of capitalist logic over the entirety of life (the "social factory"). Here I explain how the lack of access to data that Uber collects about its drivers (e.g. how many actively use the platform, what is the hourly income, etc.) impacts isolation as a subjective domination of alienation. Thin connections and a preeminent state of suspicion represent the two examples of subjective isolation amongst Uber drivers.

Uber continually collects data during travels and sends it "to Uber's servers for processing and long-term storage" (Carino 2018). If a driver is speeding or harshly braking, or if the app tracks any additional safety concerns, Uber will warn or cut off such drivers from the platform (2018). Despite the significant influence of data over their employment, drivers in the United States do not have the right to "access, analyse and act on the personal data that platform employer holds on them" (Farrar 2019). For instance, Uber does not release "complete GPS records" (2019). Neither are Uber drivers able to know how many other drivers are using the platform at any given time. According to one informant, the displayed number of drivers on the radar app was limited to seven or eight, though the number of active drivers might be higher. Sainato (2019) also discusses how "rideshare drivers around the United States reported changes in pricing models that raise fares for riders while hiding the price hikes from drivers". As a result, study informants said that they never knew if it was a good time to drive or not, that they did not support each other and that they showed no internal group commitment.

In one case, I witnessed a group of drivers at the Tampa International Airport transportation staging area complaining about how the job slowed down because of market oversaturation. At that point, one man shouted that he came from Orlando, and he did not see any problem with Uber drivers from Orlando coming to drive in Tampa. He stated that the United States is a "free country" and "free market economy" where no one can prevent another person from working where they pleased. 
His response caused a chain reaction of verbal assaults and accusations from the local drivers. They claimed that no one could prevent him from working, but that it was because of people like him that they could not earn enough. Although drivers share the same concerns and similar goals, they are unable to see a bigger picture or the ways in which their problems overlap (evidencing isolation).

Another driver stated that he felt "a bond" with another Uber driver only once, when he was picking up pancakes at a breakfast place and an individual greeted him with the words "Oh, you are doing Uber, how is it going?" He replied briefly and saw the same man once more. He never made any close friendships or connections with other Uber drivers. Uber benefits from the lack of transparency, leaving drivers estranged from the possibility of seeing how their problems overlap.

According to one informant, the way Uber controls data and its algorithm "has been purposefully oriented to keep drivers as one little person in this entire cog of things, which isolates them from other co-workers". If this reality had not been the case, he continued, "drivers would start to talk and say maybe we could do something better. Perhaps we can get paid more, and maybe we could get something more out of this relationship with Uber". The company obviously "does not want that kind of stuff", the driver concluded.

Furthermore, drivers feared that Uber could use their opinions and assessments against them, making them fear losing their jobs (i.e. being deactivated) and leading to preeminent suspicion (isolation) between drivers.

For instance, Teamsters in Seattle, Washington, collaborated "with taxi fleets, drivers, and the city" to enable "independent contractors working for Uber to form unions and engage in collective bargaining" (Johnston and Land-Kazlauskas 2018, 27). Uber immediately responded to "unsuitable" conduct by initiating a massive campaign against drivers' efforts to unionise (Johnston and Land-Kazlauskas 2018, 27). The company also invited drivers who were anti-union-oriented to testify about "fears" related to the Teamster initiative (the imposition of work uniforms, adherence to set hours, etc.) $(2018,27)$. Drivers who engaged and advocated against Uber policies were deactivated or permanently banned from the platform $(2018,27)$.

Similarly, a driver who shared his experience on efforts to train other Uber drivers to organise evaluated the task as extremely challenging because of isolation. $\mathrm{He}$ explained that drivers often tried to monetise the collective process for short-term personal gains, or decided not to mobilise against Uber. By studying how drivers turned Uber's app against Uber, I learned how isolation, an aspect of alienation, averted initially successful mobilisation (stemming from dissatisfaction and powerlessness, which are also elements of alienation) from developing into a more sustainable and effective movement.

\section{Uber App against Uber}

This section aims to show how alienation led Uber drivers to mobilise collectively by re-appropriating the app from a mode of control and surveillance into a tool to increase drivers' earnings and confront the company's arbitrary decision-making.

History includes a range of examples of situations where people used the power of rulers against them. During the era of colonialism, people of Algeria "reappropriated the radio from a tool of French colonial domination to a weapon of resistance" (Funke and Wolfson 2014, 1). Radio became "a tool of information, connection, and unification" $(2014,1)$. Similarly, Uber drivers realised that the only way to boost their earnings in response to frequent changes in the rate that Uber paid would be the re-appropriation of technology. As I have noted, while modern technologies 
serve as means of labour exploitation and domination, they also enhance possibilities for labour cooperation and liberation between diverse sectors and industries (Fuchs 2018, 524; Hope 2018, 569). This is what Uber drivers did when they used the Uber app illegally against Uber.

I interviewed one of the former Uber drivers who participated in the reappropriation of the Uber app and, based on his insights and other available online sources (e.g. news articles reporting about protest activities at the time), I learned that Uber cut fare rates for drivers in Tampa by 30\% in December 2015. Prices had been $\$ 2$ per mile, $\$ 1$ per minute for Uber $X$ and Uber Select in Tampa. Consequently, a group of drivers organised to "screw the system by manipulating the surge model and increasing their earnings" after the company dropped the pay rates. The same informant felt that "Uber's policies were like a cycle beyond drivers' control" (a reference to powerlessness). Another informant also asserted that Uber would manipulate dynamic pricing by keeping the pay rates high until more drivers joined the platform, and then suddenly cut the pay rates to attract more users, which drivers found "unfair and frustrating" (this refers to dissatisfaction).

Other drivers felt betrayed because of the sudden shifts in Uber's policies and pricing. For example, one driver bought a $\$ 40,000$ Lincoln Town Car to drive for Uber: when unable to earn enough through Uber, he was then encumbered with his car loan. Based on his interpretation, when Uber first started operating in the new city, the company offered excellent pay. In 2015, many people in Tampa decided to leave their stable jobs to drive Uber. Once Uber solidified, the situation changed overnight and drivers could do nothing to reverse the trend.

Dissatisfaction and powerlessness led drivers to gather at the airport car park waiting for requests, accepting them, and then failing to pick up their fare at the terminal. They continued to do this all night long and did not answer their phones. They also knew which time would be busiest at the airport. They waited until approximately 50 or 60 drivers were in the queue, while the app would show only five or six. They paused for the right moment when prices escalated, and then turned around and accepted rides. Drivers did this during weekend club nights, sporting events, and at the airports.

According to the official statement and based on the Technology Services Agreement (2015), the drivers' behaviour was illegitimate. Per the Agreement (2015, 7), drivers immediately consent to any changes in Uber's policy by accepting the ride (including the difference in pay rates). The same Agreement $(2015,4)$ also obligates drivers to behave in a way so as not to cause "degradation or harm of the company or any of its affiliates, its brand, reputation, or business". Therefore, Uber permanently deactivated drivers who organised protests the following day and accused them of "defrauding Uber and its users", in the words of an informant.

Regardless of Uber's deactivation of some drivers from the platform, other drivers continued to manipulate surges collectively. For instance, they assembled in car parks in downtown Tampa on Saturday nights. All drivers went online and formed the line of cars, such that one Uber driver's car was lined up with three or four regular cars, until Howard Avenue became packed with vehicles. All Uber drivers kept their doors locked and windows up. They accepted the rides, but they never moved, thus creating physical and digital gridlock. Drivers also did this in Soho.

Mobilisation happened through the appropriation of Uber's app. Drivers used the app to coordinate surge manipulations as well as numerous street protests that took place around that time. Two months later, the higher pay rates were restored. How- 
ever, isolation prevented the formation of a community among drivers in Tampa Bay. Mobilisation did not sustain.

One informant drew an exceptionally insightful comparison between earlier times and the factors that make Uber drivers' organisational prospects more challenging. The illustration was as follows: historically, during the industrial age, some industries tried to break the unions by instituting in dependent contracts between miners and companies. Therefore, the informant suggested, hiring independent contractors was not an innovation of the gig economy. Numerous miners had individual contracts with their employers during these times. Those miners also needed their equipment, and half the time would get paid what they called a script, valid for purchasing only at the employer general stores. Thus some miners would not even get a pay check, according to my informant. Uber pays its drivers 'real' money, but Uber drivers are treated the same way as elucidated miners. Instead of having drivers hired as employees and paying them the living wage and benefits, Uber hires independent contractors who absorb all the responsibilities (providing the vehicle or enduring costs of renting one, maintenance, insurance, etc.).

Additionally, the technological 'sophistication' of platforms provides more opportunities for the consolidation of capitalist power and profit, as drivers may be arbitrarily deactivated and permanently removed from the platform in seconds. Extremely high turnover rates also increase isolation because drivers rarely have a chance to learn about shared problems. Neither can they envision intergroup power relations of a different kind. Instead, Uber drivers mobilised only with a "sense of immediacy" (e.g. unfair treatment and financial necessity) (Johnston and Land-Kazlauskas 2018, 14).

Eventually, one driver explained the contradiction between the few pros of the gig economy and the commitment to participate: "[P]eople do things which they do not necessarily want to or which are not good for them; but, in capitalism, people do not have a choice because of the circumstances and financial reasons". This article concludes that the price of the flexibility of working 'on-demand via apps' is too high compared with the economic and social deprivation of workers.

\section{Conclusion}

The overarching purpose of this article was to examine material (objective) and physiological (subjective) aspects of alienation amongst Uber drivers. Between many physiological manifestations, I concentrated on dissatisfaction, powerlessness, and isolation. Combined, dissatisfaction and powerlessness led ride-hailing drivers to collectively organise against Uber by re-appropriation of the Uber's app, while isolation averted the outgrowth of loosely defined autonomous struggles into a more sustainable movement.

My analysis confirms the profoundly political nature of alienation and recognises the transformative power of technology in the hands of capitalists and workers. I articulate that the power dynamics could change in the workers' favour only through a collective struggle targeting "the indispensable logic defining capitalism" (Smith 2018, 260). However, isolation often precludes gig workers from organising en masse to disrupt the asymmetrical division of power between capitalists and workers. In the meantime, by arbitrarily collecting and controlling data, capitalists increase control, surveillance, and the appropriation of surplus from workers.

In light of the "social factory", capitalists successfully use technology to mystify social antagonisms and extend control of the "factory" over the whole society (Tronti $2019,60)$. The more capital blurs the line between "the force that creates value and 
value itself" and "surplus-value and the value of labour-power to itself", the more it obscures alienation (exclusion of workers from the product) (Tronti 2019, 50). Although hidden and difficult to operationalise and study empirically, alienation in the gig economy represents an underlying condition of gig workers' passivity, but also of their struggle and specific strategies for resistance. Most importantly, alienation provides explanatory power for collective struggle beyond drivers' re-appropriation of Uber's app in the United States, including the more recent landmark victory of Uber drivers in Britain over employment status, and class action lawsuits in many other countries across the EU (Moyer-Lee 2021).

\section{References}

Acevedo, Deepa Das. 2018. Unbundling Freedom in the Sharing Economy. Southern California Law Review 91 (5): 793-838.

Anwar, Amir. 2018. How Marx predicted the worst effects of the gig economy more than 150 years ago. NS Tech. August 8. Accessed May 7, 2020. https://tech.newstatesman.com/guest-opinion/karl-marx-gig-economy

Carino, Joseph. 2018. Uber Driver Tracking and Telematics. Geotab, January 15. Accessed June 15, 2019. https://www.geotab.com/blog/uber-driver-tracking/

De Stefano, Valerio. 2016. The rise of the «just-in-time workforce»: On-demand work, crowdwork and labour protection in the "gig-economy». Conditions of Work \& Employment Working Papers 71. Geneva: International Labour Organization. https://www.onlabour.org/wp-content/uploads/2016/05/wcms 443267.pdf

Diab, Ramon Salim. 2019. Capital's Artificial Intellect Becoming Uber's Means of Autonomous Immaterial Production. Historical Materialism 27 (1): 125-154.

Dyer-Witheford, Nick. 2015. Cyber-Proletariat: Global Labour in the Digital Vortex. London: Pluto Press.

Farrar, James. 2019. Why Uber must give its drivers the right to all their data. New Statesman America, April 2. Accessed August 1, 2019.

https://www.newstatesman.com/america/2019/04/why-uber-must-give-its-drivers-right-alltheir-data

Fuchs, Christian. 2018. Karl Marx \& Communication @200: Towards a Marxian Theory of Communication. In Marx@200: Debating Capitalism \& Perspectives for the Future of Radical Theory, edited by Christian Fuchs and Lara Monticelli. tripleC: Communication, Capitalism \& Critique 16 (2): 518-534.

Fuchs, Christian. 2020. Communication and Capitalism: A Critical Theory. London: University of Westminster Press. doi: https://doi.org/10.16997/book45

Funke, Peter N. and Todd Wolfson. 2014. Class In-Formation: The Intersection of Old and New Media in Contemporary Urban Social Movements. Social Movement Studies: Journal of Social, Cultural and Political Protest 13 (3): 349-364. doi:10.1080/14742837.2013.831755

Geertz, Clifford. 1973. The Interpretation of Cultures: Selected Essays. New York: Basic Books.

Gig Economy Data Hub. 2020. How many gig workers are there? Accessed March 5, 2020. https://www.gigeconomydata.org/basics/how-many-gig-workers-are-there

Harvey, David. 2018. Universal Alienation. In Marx@200: Debating Capitalism \& Perspectives for the Future of Radical Theory, edited by Christian Fuchs and Lara Monticelli. tripleC: Communication, Capitalism \& Critique 16 (2): 424-439.

Hope, Wayne. 2018. Epochality, Global Capitalism and Ecology. In Marx@200: Debating Capitalism \& Perspectives for the Future of Radical Theory, edited by Christian Fuchs and Lara Monticelli. tripleC: Communication, Capitalism \& Critique 16 (2):562-567.

Hyman, Louis. 2018. Temp: How American Work, American Business and the American Dream Became Temporary. New York: Viking. 
Johnston. Caitlin. 2019. Lawsuit: Hillsborough's new taxi permits cost drivers thousands.

Tampa Bay Times. July 12. Accessed April 1, 2020.

https://www.tampabay.com/transportation/lawsuit-hillsboroughs-new-taxi-permitscostdrivers-thousands-20190711/

Johnston, Hannah and Chris Land-Kazlauskas. 2018. Organizing on Demand: Representation, Voice and Collective Bargaining in the Gig Economy. Conditions of Work and Employment Series 94. Geneva: International Labour Organization. Accessed April 17, 2019. https://www.ilo.org/wcmsp5/groups/public/---ed protect/---protrav/--travail/documents/publication/wcms 624286.pdf

Kayıhan, Bahar. 2018. An Analysis of Marx's Legacy in the Field of Communication Studies. In Marx@200: Debating Capitalism \& Perspectives for the Future of Radical Theory, edited by Christian Fuchs and Lara Monticelli. tripleC: Communication, Capitalism \& Critique 16 (2):628-638.

Lamas, Andrew T., Todd Wolfson, and Peter N. Funke. 2017. The Great Refusal: Herbert Marcuse and Contemporary Social Movements. Philadelphia: Temple University Press.

Mason, Sarah. 2018. High score, low pay: why the gig economy loves gamification. The Guardian, November 10. Accessed January 12, 2019.

https://www.theguardian.com/business/2018/nov/20/high-score-low-pay-gamification-lyftuber-drivers-ride-hailing-gig-economy

McMorrow-Hernandez. Joshua. 2016. Tired of driving? Ride-hailing services ready to help transform Tampa Bay transportation scene. 83 Degrees Media, January 12. Accessed August 1, 2019. https://www.83degreesmedia.com/features/ridesharing011215.aspx

Moyer-Lee, Jason. 2021. UK Supreme Court's Uber decision is a victory for all gig workers. Al Jazeera. February 25. Accessed April 2, 2021.

https://www.aljazeera.com/opinions/2021/2/25/the-uk-supreme-courts-uber-decision-is-avictory-for-all-workers

Munn, Luke. 2019. Cash Burning Machine: Uber's Logic of Planetary Expansion. tripleC: Communication, Capitalism\& Critique 17 (2):185-201. doi: https://doi.org/10.31269/triplec.v17i2.1097

Ollman, Bertell. 1971. Alienation: Marx's Conception of Man in Capitalist Society. London: Cambridge University Press.

Oyer, Paul. 2020. The gig economy: Non-traditional employment is a great opportunity for many, but it won't replace traditional employment. IZA World of Labour. doi: 10.15185/izawol.471

PBS NewsHour. 2019. How data drives Uber's efficient but controversial business model. Streamed May 2, 2019 at YouTube, Video, 8:37. https://www.youtube.com/watch?v=63wt3TgGGxI

Rasier Technology Services Agreement. 2015. Rasier, LLC (-CA, -PA, -DC, -MT). Hinter-NM. Uber Driver app. Accessed June 3, 2018. https://apps.apple.com/us/app/uberdriver/id1131342792

Rasier Addendum. 2017. Uber Driver app. Accessed June 3, 2018. https://apps.apple.com/us/app/uber-driver/id1131342792

Sainato, Michael. 2019. Uber and Lyft drivers say apps are short-changing wages while raising fares. The Guardian, April 18. Accessed December 1, 2020. https://www.theguardian.com/technology/2019/apr/18/uber-lyft-drivers-surge-pricingwages

Schensul, Stephen L., Jean J. Schensul and Margaret D. LeCompte. 2012. Initiating Ethnographic Research: A Mixed Methods Approach. California: AltaMira Press.

Schiller, Ben. 2017. You Are Being Exploited by the Opaque, Algorithm-Driven Economy. Fast Company, August 4. Accessed December 7, 2019. https://www.fastcompany.com/40447841/you-are-being-exploited-by-the-opaquealgorithm-driven-economy

Shapiro, Aaron. 2019. Dynamic Exploits: The Science of Worker Control in the On-Demand Economy. Media, Inequality \& Change Center. 
Smith, Tony. 2018. New technology and the 'new economy'. In The Elgar Companion to Marxist Economics, edited by Ben Fine, Alfredo Saad-Filho and Marco Boffo, 259-

264. Cheltenham: Edward Elgar Publishing Limited.

Torpey, Elka and Andrew Hogan. 2016. Working in a gig economy. Career Outlook, May 16. Accessed March 24, 2020. https://www.bls.gov/careeroutlook/2016/article/what-is-the-gigeconomy.htm

Tronti, Mario. 2019. Workers and Capital. Translated by David Broder. London: Verso. https://www.versobooks.com/books/2962-workers-and-capital

Tucker, Robert C. 1978. The Marx-Engels Reader. Second edition. New York: W.W. Norton \& Company.

Uber. 2018. How to take trips toward a specific location. Accessed June 10, 2018. https://www.uber.com/us/en/drive/basics/driver-destinations/

Witheford, Nick. 1994. "Autonomist Marxism and the Information Society." Capital \& Class, no. 52 (March): 85.

http://search.ebscohost.com.ezproxy.lib.usf.edu/login.aspx?direct=true\&db=edsgao \&AN= edsgcl.15325053\&site=eds-live.

Wolfson, Todd and Peter Funke. 2018. The History of all Hitherto Existing Society: Class Struggle and the Current Wave of Resistance. In Marx@200: Debating Capitalism \& Perspectives for the Future of Radical Theory, edited by Christian Fuchs and Lara Monticelli. tripleC: Communication, Capitalism \& Critique 16 (2):577-587.

World Development Report. 2019. International Bank for Reconstruction and Development/ The World Bank. Accessed March 11, 2021. http://documents1.worldbank.org/curated/en/816281518818814423/2019-WDRReport.pdf

Zuboff, Shoshana. 2019. The Age of Surveillance Capitalism: The Fight for a Human Future at the New Frontier of Power. New York: Public Affairs.

Zwick, Austin. 2018. Welcome to the Gig Economy: Neoliberal industrial relations and the case of Uber. GeoJournal 83 (4): 679-691.

\section{About the Author}

Dragana Mrvos

Dragana Mrvos holds a Ph.D. in government from the University of South Florida, where she also teaches. Her dissertation, "Proliferation of Gig Platforms and Its Impacts on Labour in a Study of Uber and CarGo" examines the new forms of labour exploitation under ride-hailing platforms and how implications of exploitation spread beyond the economy. Her areas of research and teaching include workers' participation and self-management, human rights and technology, and social movements. 